\title{
Academic Accreditation Process of English Language Institute: Challenges and Rewards
}

\author{
Dr. Aishah Khojah ${ }^{1} \&$ Dr. Amal Shousha ${ }^{2}$ \\ ${ }^{1}$ Assistant Professor in linguistics, Head of Quality \& Development Unit, English Language Institute, Women \\ Main Campus, King Abdul Aziz University, Saudi Arabia \\ ${ }^{2}$ English Language Instructor (PhD. in Applied Linguistics), Accreditation Section Coordinator, English \\ Language Institute, Women Main Campus, King Abdul Aziz University, Saudi Arabia \\ Correspondence: Aishah Khojah, Assistant Professor in linguistics, Head of Quality \& Development Unit, \\ English Language Institute, Women Main Campus, King Abdul Aziz University, Saudi Arabia. Tel: \\ 96-650-365-0780. E-mail: akhojah@kau.edu.sa
}

Received: March 29, 2020

doi:10.5539/hes.v10n2p176
Accepted: April 22, $2020 \quad$ Online Published: April 25, 2020

URL: https://doi.org/10.5539/hes.v10n2p176

\begin{abstract}
Accreditation plays a vital role in promoting self-assessment and excellence in English language teaching and administration. It ensures high quality teaching, and provides proper tools and various types of educational support for productive learning to take place. In this connection, the present research is a case study to assess the academic and administrative practices based on the accreditation and reaccreditation experiences of the English Language Institute (ELI), female section, at King Abdul-Aziz University in Saudi Arabia. It aims to document both initial accreditation and reaccreditation and the changes that are fostered. It also aims to report accreditation challenges along with its impact on administrative and academic levels. Semi-structured interview was used to collect data for the study. The study participants were ELI faculty and administrators who were involved in the accreditation process. The findings revealed a positive impact of accreditation on the ELI administrative and academic practices in terms of organizational structure, work atmosphere, and cultural influence.
\end{abstract}

Keywords: accreditation, challenges, impact, management, administration, academic

\section{Introduction}

Accreditation is the recognition that an educational institution maintains suitable standards. It ensures high quality of teaching, and provides the students with qualified instructors and proper tools and services for productive learning. It can be granted in different ways based on the nature of the institution and the program in request. In addition to the institutional accreditation of King Abdulaziz University (KAU) by the Saudi National Commission of Academic Accreditation \& Assessment (NCAAA), the English Language Institute (ELI, established in 1975 at KAU) was internationally accredited by the Commission on English Language Accreditation (CEA) for the quality of its intensive English language program offered to regular preparatory year students (ELI PYELP, started in 2008). CEA is a US-based institution recognized by the US Secretary of Education as the only specialized accrediting agency for English language programs and institutions in USA. It also accredits International (non-US) programs and institutions. Its mission is to promote excellence in the field of English language teaching and administration. This mission is achieved by advancing widely-held standards to foster continuous program development through a rigorous process of regular self-assessment and peer evaluation, (CEA website).

In 2013, ELI PYELP was accredited for a five-year initial accreditation which was followed by a ten-year accreditation in 2018 to become the first English program in Saudi Arabia to be accredited by the CEA. In order to achieve the two levels of accreditation, the ELI underwent challenging processes. It started with understanding more than fifty CEA individual standards which are included under eleven standard areas. These areas are: mission, curriculum, faculty, facilities, equipment and supplies, administrative and fiscal capacity, student services, recruiting, length and structure of the program, student achievement, student complaints, and program development, planning and review. These standards act like benchmarks of good professional practice with students, staff and faculty "which is helpful in determining why the institution is, or is not, achieving its mission and broad-based goals, and in interpreting the results of the outcomes assessment process" (Sywelem, 2014, p. 
7).

The ELI accreditation team was carefully selected in order to best achieve the accreditation project. The team was headed by the self-study coordinator, whose dedication and sincere efforts were very much appreciated. The selection of the accreditation team was crucial to the overall operational effectives of the accreditation process because the "team can offer a more summative evaluation and an objective external perspective that can potentially strengthen the institution" (Ryhan, 2013, p. 92).

Being part of this team, the researchers were totally immersed in the accreditation process. The principal researcher, Head of Development Unit in Women campus from 2015 to the present, managed the accreditation process and oversaw the writing of self-study report sections relevant to Women's Campus. The associate researcher coordinated the process, wrote part of the report sections, collected the supporting documents and raised accreditation awareness among faculty, staff and students.

The accreditation process consisted of six steps: application for eligibility, accreditation workshop, self-study plan, self-study report, site visit, review and final decision by the commission. First, the application form was completed according to CEA guidelines. Based on CEA review of the submitted documents (i.e., curricular documents, a list of faculty and staff with training and experience, information about student services, and the administrative structure), ELI was found to be eligible for review by CEA.

Second, after meeting eligibility requirements, ELI representatives were invited to attend a 2-day workshop in which participants learned more about the standards, received guidance on how to complete the self-study report, and were given an overview of the site visit and review for accreditation decision by the Commission.

Third, two weeks after the workshop, ELI submitted the self-study plan which included a timeline for the self-study, a target date for the site visit, and a list of accreditation committees and members.

Fourth, writing the self-study report was the most important step. It was a self-assessment and reflective process in which ELI had to demonstrate how well it met the 52 CEA standards in the initial accreditation and the 44 standards in the re-accreditation, provide documents as evidence of so doing, and recommend areas of improvement. Drafting the self-study report in the re-accreditation process started in May 2016 and ended in July, 2017.

Fifth, a five-member CEA review team read the self-study report prior to conducting a 3-day site visit. Taking place in December 2017, the visit included ELI classes and facilities, and interviews with administrators, faculty, and students in order to verify the contents of the self-study report. Subsequently, the review team report was received by and responded to by ELI. The review team report in the initial accreditation and re-accreditation stated that ELI fully met all the standards.

Finally, the accreditation decision by the 13-member CEA Commission was based on the self-study report, the review team report, the response from ELI, and a review of finances. The final decision granted ELI initial accreditation for five years in April 2013 while the ten-year re-accreditation was granted in April 2018. It is important to emphasize in this connection that CEA accreditation is an internationally recognized demonstration of ELI commitment to academic excellence and management transparency. This commitment is ongoing and intensive; and ELI compliance with CEA standards is proven annually in a report submitted to CEA.

In completing the accreditation process, ELI members in Women Campus encountered some challenges (see 4.4) that added to their professional experiences. These challenges were mainly in implementing accreditation requirements. Later, this encouraged them to adopt the idea of accreditation for development and high quality achievements. Given such accreditation experiences, this study attempts to explore the concept, challenges and the impact of accreditation on the ELI managerial, administrative and academic activities. To the researchers' best knowledge, there is no previous research has to date been undertaken to assess accreditation or reaccreditation processes of a language institution in Saudi Arabia. Thus, there arose the need to conduct this study in order to document the ELI accreditation experience, and bridge such an essential research gap. In so doing, this study will attempt to answer the following questions:

a. What does accreditation mean to members at the ELI?

b. What are the challenges that ELI members faced in implementing the accreditation requirements?

c. What is the impact of accreditation on ELI academic and administrative activities?

\section{Literature Review}

\subsection{What is Accreditation?}

Accreditation is a process of validation in which colleges, universities and other institutions of higher education 
are evaluated based on the quality of education they offer to their students. It is a process to promote self-assessment, quality improvement and excellence in the field of English language teaching and administration. The literature basically relates accreditation to quality assurance. For instance, (Dey, 2011) and (Sywelem, 2014) stated that accreditation stands for assuring quality and assessing the measures for efficient application of plans to attain stated goals. (Fertig, as quoted in Collins, 2015, p. 149) characterized accreditation by "a duality between meeting standards in the context of a significant period of self-analysis and improvement". Other scholars said accreditation is "the primary process for assuring and improving the quality of higher education institutions by providing assurance that a program or institution meets established quality standards" (Brahimi, Sarirete, and Ibrahim, 2016, p. 52). Nevertheless, some writers considered accreditation as a matter of certification that "an institution or a specific program processes educationally appropriate objectives that are being achieved" (Islam, Ali, \& Zohurul Islam, 2017, p. 281). Generally speaking, accreditation is used for quality of standards. According to (Ryhan, 2013, p. 93) accreditation is "a game for achieving a high-quality, uniform and standardized status". More specifically, (Ryhan, 2013) stated that accreditation is a quality practice that institutions of higher education undergo in order to reassure that they perform well, satisfy their customers and be committed to the implementation of quality practices. In short, many writers agreed that accreditation fosters quality assurance and quality improvement, (Ulker and Bakioglu, 2018) found out that accreditation has a positive effect on academic quality as it improves the processes and practices in a newly established program or institution during the initial accreditation process.

There are mainly two types of accreditation in Saudi Arabia; national and international. As mentioned above, the national accreditation is provided by the NCAAA which was set to accredit Saudi educational institutions. (AlMohaimeed, Midhet, Barrimah \& Saleh, 2012, p. 24) defined institutional accreditation as "a process whereby officially appointed external regulatory bodies, accountable at government level, evaluate educational institutions sing established criteria, standards and procedures". By contrast, the international accreditation is, by definition, granted by accreditation agencies outside Saudi Arabia and approved by the Ministry of Education in the Kingdom. According to (Harry, 2002, p. 4), "The government recognizes accreditation agencies as providing a framework for evaluating quality but they are not statutory bodies". CEA, mentioned earlier, is an example of an international accreditation agency. However, the essence of accreditation is the same in both types.

\subsection{Usefulness and Challenges of Accreditation}

Many writers agreed that accreditation fosters quality assurance and quality improvement. For example, (Ulker and Bakioglu, 2018) found out that accreditation has a positive effect on academic quality as it improves the processes and practices in a newly established program or institution during the initial accreditation process. This effect is done by a period of self-study against set of standards which act as a benchmark or quality threshold. (Ryhan, 2013; and Veries, 2014) assured that the self-study provides an opportunity for reflection to determine both strengths and weaknesses for improvement. (Collins 2015, p. 143) suggested "by working through standards during the self-study process, institutions have the opportunity to design and implement a suite of individual initiatives in the hope that improvement occurs". Among the benefits for teachers, he mentioned transparency, professionalism, documentation, future career opportunities, better professional development, appraisals, and more formal and effective feedback channels between admin, faculty and staff. (Ryhan, 2013, p. 95) also agreed on the benefits of accreditation by saying that "Accreditation protects the interests of students, the academic institutions themselves, and potential employers, by ensuring that the educational programs offered have attained a level that meets or exceeds standards that were developed by experts in the field".

Furthermore, in his study, Al Mohaimeed et. al., (2012) summarized the benefits of accreditation on the academic level. They showed that students' learning outcomes were significantly improved. Students can easily read the course specification before they enroll into the program. As a result, curriculum is reviewed regularly for improvement. Also, a complete record of students' performance is included in the course report. The students have clear acknowledgment about the assessment procedures from the beginning of the course. The students are academically assisted by their instructors during office hours. Moreover, the students are encouraged to be more involved in extra-curricular and sports activities.

On a practical perspective, students benefit from accreditation when they have "a quality learning experience," (CEA website http://cea-accredit.org/students). CEA accredited programs and institutions have met most of the requirements listed below:

- They have a published mission that guides activities, policies, and allocation of resources.

- They have a curriculum focused on meeting the assessed needs of students. 
- They maintain an effective system for assessing students for initial placement in courses and for progression from level to level.

- They maintain experienced, professionally qualified faculty that are committed to teaching.

- They have facilities and administrative and fiscal resources to provide an excellent learning environment.

- They provide a wide array of student services - on-going orientation; academic personal, visa, and immigration advising; and social, recreational, and cultural activities.

- They are pledged to use ethical recruiting practices; all promotional literature has been deemed to be accurate and complete and to fully inform students of what benefits they will receive from their tuition.

- They have in place formalized plans to continually review and revise programs and services, (CEA website http://cea-accredit.org/students).

The merit of accreditation is emphasized by (Veries, 2014) as reflection on what you are doing, which curriculum you are using, why you are using it, whether things are going as planned and where improvements are required.

On the other hand, not many challenges of accreditation were listed in the literature. (Collins, 2015), for instance, assured that accreditation focuses more on the process rather than on improvements at classroom level, imposes ideas on individuals and increases the workload. To some researchers, accreditation concentrates more on the process rather than on the learning experience, "External evaluation, in legitimating the status quo, fails to ask significant questions about the reality of the learning experience for students at a momentous historical juncture for post-compulsory education. Evaluators appear to be preoccupied with the method of evaluation rather than the substance" (Harvey, 2002, p. 245). He added "quality monitoring [needs to] engage more directly and explicitly with innovations and improvements in learning and teaching" (Harvey, 2002, p. 245). In addition, (Karaferye, 2017) criticized the process of accreditation as it is a time consuming activity, challenging, and exhausting due to increased workload. Nonetheless, in order for self-evaluation process to be more open, honestly reflective and useful, the evaluation process has to be less threatening (Harvey, 2002). The following section reveals more of real benefits and challenges that some educational institutes encountered during accreditation process.

\subsection{Accreditation in Educational Institutes}

A number of international higher education institutions seek accreditation in order to attract international students. As a result, they are obliged to implement the standards that are established by the accreditation agencies. (Collins, 2015) evaluated the impact of international accreditation granted by CEA to the intensive English language preparatory program in a university in Turkey to foster changes in the organizational structure. He found out that changes were mainly administrative and managerial more than academic. In addition, he maintained that accreditation could be an effective tool if used properly. The institution also provided more professional development activities. He concluded that in operating an educational institution, the indirect benefits of accreditation are more important than the direct ones in changing staff beliefs. Finally, changing organizational culture is a complex process that could not be achieved only by accreditation.

(Ryhan, 2013) elaborated on the process of international accreditation provided by Council of Occupational Education (COE) and awarded to Jazan Community College (JCC) for three years and five years respectively. He illustrated the challenges faced during this process on the technical, social and managerial levels. The technical challenges were faced when measuring and evaluating JCC practices against COE ten standards. He listed a number of social and managerial challenges:

- Accreditation is money and time consuming activity.

- Failure to change the behavior and attitude of people.

- Unwillingness to participate in the process of accreditation and circumvent from extra work during the course of self-study report writing.

- Resistance to accept change and negative approach to nullify improvement.

- Training of staff, students, administration on concepts of accreditation.

He suggested that institutions need a change in attitude and a sense of ownership with regard to the quality of services provided by JCC to sustain improvements. He also added, supporting initiatives are highly needed to integrate accreditation into the structure and function of an organization.

Nevertheless, he listed the following benefits of accreditation to JCC:

- Raising student achievement.

- Enhancing the ability to serve students by assuring a focus on quality performance. 
- Providing excellent equipment, software and learning resources for students.

- Providing recognition of the ability to serve community stakeholders.

- Creating the impetus for relevancy and currency of faculty, programs and courses to best serve employers.

In his review of accreditation procedures, (Karaferye, 2017) specified the accreditation process entailed by the most preferably accrediting agencies in Turkey; CEA and Pearson Assured. He stressed on the importance of the involvement of all employees in the process from the upper management level to the lower level in spite of the fact that academic staff complained of increased workload. He witnessed motivation, interaction and support of all employees as vital to gaining accreditation.

Accreditation in Netherlands and Flanders is compulsory and has serious consequences (Van Kemenade et al., 2010). They believe that control has a negative effect on the willingness to contribute to the accreditation process, and as a result it should be separated from improvement. They proposed that accreditation should be based on document analysis and a site visit, and that the self-study should be a voluntary act done by the institution itself in an improvement process.

In short, the literature indicated that accreditation has benefits and challenges; supporters and opponents. In the process of implementing accreditation, a lot of challenges are expected to be met. However, we believe that accreditation's benefits to any accredited program or institution on the management, administrative and academic levels overweigh these challenges, and the fact remains that accreditation has become "part of the ever-increasing globalized battle for students and for qualified faculty and staff" (Collins, 2015, p. 143).

\section{Methodology}

\subsection{Research Strategy and Design}

A case study design is used in this work in order to explore the nature of accreditation in a real-life context, namely ELI at KAU. The study adopted the qualitative approach through semi-structured interviews for data collection and analysis. For ethical consideration, an institutional consent was granted by the ELI Vice Dean to conduct the interviews for the completion for the research. Moreover, the faculty members who agreed to participate were given an information letter that explains the topic and the process of the study. It also explains the potential outcomes of the study to the ELI and to other educational institutes. The letter also states that the interviews will be used for the research purpose only and the participants have the right for anonymity and confidentiality. Accordingly, the participants signed the consent form.

All recorded interviews were fully transcribed in English and then carefully analyzed. The most important factors given by the participants were highlighted and grouped into these thematic areas: impact of accreditation on management, administrative, and academic levels, challenges faced and solutions. These themes were compared to the ones highlighted in the literature. The interview questions were as follow:

1- What does accreditation mean to you?

2- What was your idea about accreditation before the project and what is your idea about it now?

3- How was it helpful to you in your job (impacts on academic level, management level, admin level)?

4- How can it improve ELI?

5- What were the changes implemented to get accreditation?

6- What were the challenges faced (in writing the reports/ before and during the site visit)?

7- How did you overcome the challenges?

8- What are the benefits of accreditation?

\subsection{Participants}

The participants were selected based on the assumption that they possess the knowledge and experience related to the research topic and aim. They were actively involved in accreditation or they played a precise role in the process of accreditation. Therefore, they were able to provide detailed in-depth information to answer the research questions. The interviewed participants were ELI stakeholders. They were chosen from ELI top management, administrators, and teachers. The total number of participants was 12 . They were current and former Unit Heads, Section Supervisors, administrative staff and instructors. They all participated in one or more than one of the accreditation activities, such as attending accreditation awareness workshops, preparing self-study reports, and/or being interviewed by site visit teams. For confidentiality and anonymity reasons, the participants' initial letters are used here. The demographic information of the interviewees is presented in Table 1. 
Table 1. Participants' Information

\begin{tabular}{lllll}
\hline Participant & Position & Years of experience & Participation in & Participation in \\
& & in the position & initial accreditation & reaccreditation \\
\hline E & Management & $5+$ & & \\
$\mathrm{H}$ & & $5+$ & & \\
$\mathrm{S}$ & $5+$ & $\checkmark$ & \\
$\mathrm{J}$ & & $5-$ & $\checkmark$ & \\
$\mathrm{L}$ & Admin & $5-$ & $\checkmark$ & \\
$\mathrm{A}$ & & $5+$ & $\checkmark$ & \\
$\mathrm{R}$ & & $5+$ & & \\
$\mathrm{F}$ & & $5+$ & $\checkmark$ & \\
$\mathrm{G}$ & Academic & $5+$ & & \\
$\mathrm{N}$ & & $5+$ & & \\
$\mathrm{K}$ & & $5+$ & & \\
$\mathrm{Z}$ & & $5+$ & & \\
Total & & 12 & & \\
\hline
\end{tabular}

\section{Results}

The participants' responses were grouped into three levels: management, administrative, and academic across six areas: concepts of accreditation, (Questions 1\&2), changes implemented for accreditation (question 5), impacts and improvement with accreditation (Questions 3\&4), challenges faced during the process of accreditation (Question 6), and participant's suggestions and solutions to overcome these challenges (Question 7). Finally, the results show the benefits and constraints of accreditation (questions 8 ) as they were provided by the participants.

\subsection{Concepts of Accreditation}

The interview results revealed the twelve participants' general knowledge about accreditation and their previous and current perspectives about it. Generally, the participants defined accreditation based on their positional levels. On the management level, the responses included, "meeting international standards", "consistency", "adherence to standards", "documentation", "systemic clear regulations to be followed by everyone".

Moreover, the concept of accreditation for the administrative participants was related to their daily work activities. Their responses showed "work organization", "distribution of tasks according to specialization", "having job descriptions", "clear steps and procedures to follow" and "systemization".

Accreditation was defined on a general level by the academic participants as being "officially and internationally recognized institute" and "standardization" in all aspects. In spite of its "long and tiring procedure", a participant believes it was "worthy and rewarding".

Some of the participants changed their negative views about accreditation especially after ELI was granted a ten-year of accreditation. Their early attitudes or perspectives about accreditation were different ranging from "confusion" and partial conceptions to a sincere concern about a "complicated and long process". Participant J mentioned the "imposition of the project by heads". However, the negative views were replaced by positive ones later. After the process of accreditation, there was an appreciation of accreditation process. The participants responded that accreditation became an "easy process"; it "helped developing our team work and organization"; it was "beneficial" to everyone at ELI; it "saved time and space"; the system became clearer; "accreditation gave extra value to workplace"; it was a "worthy effort"; and teachers were more dedicated to achieve targeted goals.

\subsection{Changes Implemented for Accreditation}

To apply for international accreditation, the ELI should introduce substantial changes in its academic system. Participant S explained that the "English courses at the ELI used to be taught in a 13-week academic semester. This was swapped into a 6-week module. This change was reflected in the vision and mission of the Institute". Participant H reacted that "The mission was posted everywhere and memorized by heart".

The chief administrator commented that each position in the hierarchy had its "job description", e.g. vice-dean, 
unit heads, section supervisors, coordinators, admin and staff. "All these members had to regularly communicate and meet to keep everyone on track and to know the points of struggling and facilitate them to ensure that the target is being achieved", as participant $\mathbf{J}$ responded. She reported that "this helped to foster a great sense of belonging". "High quality faculty was recruited as quality mattered rather than quantity," participant R added. Participant S commented that "documents of all ELI processes and meetings; e.g. meeting agendas, meeting minutes, weekly and monthly reports were kept as evidence of activities". This documentation, she prolonged, "helped towards work organization". More importantly, according to participant L, "the foundation of the testing unit improved test quality and provided curriculum guide, student guide and testing guide".

On the academic level, changes were considerable. A new internationally-recognized course books were introduced. As a result, "course objectives, course syllabus, pacing guide, weekly memos and guided classroom observation were all introduced", as participant S stated, "therefore, all teachers knew what they had to do". Participant K described that "ELI website started to be very effective and it had very useful resources for both teachers and students". "A new faculty and student handbooks were posted providing faculty and students with all the needed information such as their rights and duties", participant $\mathrm{Z}$ responded. Other teachers replied that, job descriptions for all faculty positions e.g. assistant professor, lecturer and language instructor were introduced including teaching hours and work duties. In addition, teacher $\mathrm{K}$ said that "more professional development activities were introduced in various pedagogical areas".

Furthermore, during the reaccreditation phase, changes were reasonably few compared to the first phase. Due to the growth of ELI program activities the vision and mission were revised. According to the participant $\mathrm{H}$ from the management level, "three review committees were formulated to review staffing, facilities and student services". "ELI followed the new strategy of KAU to minimize the use of paper and started applying electronic transaction, electronic staff evaluation and electronic faculty and staff files", participant E stated, "Student complaints also conducted electronically". This led to what a participant from the admonition level pointed out "more organized institute and more developed workplace". She added that "all job descriptions were updated". "On the academic level, one of the most important changes was the contents of the course books that were more culturally appropriate to the Saudi traditions", participant N replied. Moreover, "online platform; e.g. blackboard, was utilized to enhance student practice outside classrooms", as participant L stated. She continues that the "accreditation awareness PowerPoint presentations for both teachers and students helped to raise awareness among faculty and students of the importance of accreditation as well as the required standards".

\subsection{Impacts and Improvements with Accreditation}

Most of the participants on the three levels agreed that improvement in ELI was obvious after the initial accreditation and that improvement was maintained after the reaccreditation. In general, they assured that accreditation strongly helped them to organize work. In other words, CEA standards became their "reference point". There was a good understanding of ELI new organizational structure on all levels; i.e. following hierarchy in case of complaints, an administrative participant specified. All the participants witnessed the best practices in the ELI units in the light of the ELI mission and vision. The participants, H, S, J and E from the management office learned the importance of commitment and team work. "Because all rules and regulations were clear and understood by all ELI members, work duties were accomplished in less time and efforts," participant E responded. Participant J commented "Accreditation gave us an UMBRELLA on how to coordinate all the components in our institution". Another participant stated, "Errors or mistakes are not accepted; Accuracy is the goal".

On the administrative level, participant $\mathrm{R}$ responded "the staff became more confident and more aware of the professional development; as a result, their performance was highly improved". "Use of the same electronic forms in Women and Men campuses saved time, effort and space; administrator F commented, "the workplace became healthier".

Accreditation had a great impact on the academic level. "ELI teachers", as participant G responded, "started to evaluate themselves and looked for ways to improve and develop themselves professionally by attending workshops related to their needs". "Teaching became more fun and less exhausting because technology played a great role in and out the classrooms," as participant $\mathrm{N}$ reported. For example, participant $\mathrm{Z}$ stated, "it became much easier to track students' work on Blackboard and use Itool (the electronic version of the textbooks) in teaching," as a result, "teachers were satisfied of their class observation evaluation". "The whole atmosphere at ELI now is productive and helpful," participant $\mathrm{K}$ responded.

\subsection{Challenges Faced During the Accreditation Process}

The findings showed some challenges that ELI encountered during the two phases of accreditation process. Most 
of the participants' responses to the fourth interview question revolved around the challenges in writing the report and preparation for the site visit, i.e. before and/or during the visit.

On the management level, participant $\mathrm{S}$, who contributed to the report writing informed that "because there was no database, it was challenging to start from scratch to find all the required documents; and that the team found it hard to complete the forms". For documentation, it was challenging for most administrative team to create files for faculty, staff and committees. Participant F mentioned that "it was not easy to get ELI building floor plans from the project management department at the university". It was also challenging for some administrators to comprehend the accreditation standards for writing reports of their work. As a result, there was some attitudes towards the changes, a participant from the management level responded. Participant $\mathrm{N}$ assured that "The main challenges were the lack of awareness of the accreditation; some people were not convinced of its benefit to the institute. Also information needed for writing the reports were in different places; so we had to look for it in many directions".

The site visit was challenging as well; "it was a very long day, but everyone was on board, even when there was a fire alarm, evacuation of the building was done in a professional way although people were apprehensive," participant $\mathbf{J}$ remembered. There were some physical and logistical challenges such as name tags, sign boards, offices and a PC for every faculty, participant A added. Participant F reported, "It was difficult to create and implement everything before the site visit". CEA interviews and following-ups were not easy tasks, as participant $\mathrm{H}$ reflected, "it was difficult to create and implement everything before the site visit".

The challenges on the administrative level were less than expected because as administrator R stated, "the ELI administration was well organized; therefore, it was easy for them to follow the regulation and adopt new rules". However, it was challenging for some administrators to collect data and document old files for accreditation. Participant F stated, "Some people are not taking accreditation seriously, so they do things at the last minute". Another participant responded that, it was not easy to fix all problems of educational facilities in classes in a short time period. Participant N confirms, "Concerning the visit, we were worried because we thought many files would need to be completed. During the visit we were worried about those who had negative attitude towards accreditation".

On the academic level, there were not any challenges stated in regards to writing the report. However, participant $\mathrm{K}$ claimed that the time devoted to the huge amount of paperwork was her biggest challenge. "To keep my CV updated with all the professional development activates was the common challenge among teachers," participant $\mathrm{G}$ responded. "It was a bit challenging to implement the dress code and to be asked to do things till the last minute of the site visit. It was also worrying to be on time for CEA observed classes and interviews", participant $\mathrm{N}$ claimed. Stress following the standards was also mentioned. Participant L listed challenges as follows, "Collecting the data, filing and getting all employees to organize their files, analyzing reports and raising awareness of all faculty and employees about accreditation importance".

\subsection{Participant's Suggestions and Solutions}

Despite of the challenges mentioned above, the participants provided us with some solutions to the interview question on how they overcome the challenges.

On the management level, participant J assured, "It was a win-win situation," thus, she continued that the "top management support, sense of belonging and team work were essential as resorts". "Communication" and "transparency" allowed participant S and her team to have view of what were the challenges to overcome. "Awareness presentations" were mentioned at all levels to help overcome challenges; participant L confirmed, "Everyone felt that we were part of the change."

On the administrative level, to overcome the pile of paper work, most of the administrators' work was electronically conducted, e.g. students' complaints, as participant A stated. ELI staff, as participant E confirmed, "activated the electronic files at all levels of the admin work".

On the academic level, teacher G found out that "it would be easier for her to keep record of all workshops of professional development and immediately add them to her CV". Teacher K gave some suggestions that helped a great deal overcome the challenges including, "hard work, team work, dedication, feeling of belonging to the workplace, cherishing the workplace". Hence, the participants suggested to simplify the accreditation process and make it open and for all members to develop sense of belonging and team work and to accept the changes and accept the new requirements.

\subsection{Benefits and Constraints of Accreditation}

The result also recorded the benefits of accreditation as mentioned by the participants of the three levels. They 
mentioned, "worldwide recognition", "faculty were more valued in the job market", "CV becomes more attractive to employers". "Organized workplace", "documentation", "high standards", "consistency", "more collaboration" and "responsibility on everyone's shoulder" as accreditation benefits. Participant H reveals, "Accreditation helped us to put our focus right and develop in the right direction". Participant G also says, "Anyone, who believes in being well organized in her work, will find CEA a blessing and adds a lot to her work." Participant $\mathrm{S}$ believes, "Accreditation adds more responsibility on everyone's shoulders. It means we have reached a standard that should be kept".

As for accreditation constraints and drawbacks, participants mentioned that few people resisted and did not accept the changes, that accreditation brought to the Institute. A participant from the administrative level specified, "Some staff members were reluctant and were not ready to take on the change". They do not want to put effort; staff members did not want change that would add to their administrative work, as participant A responded. Some participants thought that asking about the same information over and over is hectic. Hence, the drawbacks of accreditation as mentioned by the participants included, "time consuming", "time constraints", "costs", "stress" and "resistance to change".

\section{Discussion and Conclusion}

This current study demonstrates a documentation of a case-study of ELI accreditation process. This section discusses the participants' responses to the interview questions which would provide some answers to our research question related to accreditation meaning, challenges and impact.

As for the first research question, the participants had various concepts of accreditation. Their concepts of accreditation are greatly affected by their position at the ELI. On the management level, more knowledgeable technical vocabulary and aspects from the accreditation field were used when defining accreditation as the managers are the ones who are fully aware of the standards and the self-study report writing. On the administrative level, accreditation is defined based on how it is related to their daily administrative work activities. On the academic level, accreditation is defined on a more general level, i.e. a certified program and institution. Hence, accreditation for ELI faculty means being internationally recognized, adherence to or applying standards, standardization, documentation, work organization, and clear procedures. These definitions are related to the ones found in the literature (Ryhan 2013; Fertig 2007; Collins 2015; Nazrul Islam, et. al., 2017). However, number of writers in the literature defined accreditation as "quality assurance," (Dey 2011; Sywekem 2014; Brahimi et al., 2016). This definition was not supported by ELI members who participated in this study. Although the accreditation unit works hand in hand with the quality assurance unit at ELI, the participants of this study seem to perceive of accreditation and quality assurance as two different concepts.

As for the second question of the research, the challenges ELI faced were mainly due to the establishment of a new system and matching this new system to the CEA standards. This new system entailed starting from scratch, establishing data base, collecting existent documents and improvising others, creating files and having faculty data base. These challenges fall into three categories: technical, social and managerial as exhibited in (Rhyan, 2013). Among the technical challenges are measuring and evaluating ELI practices against CEA standards, having a mission, organizational structure, and faculty appraisal. The social and managerial challenges included changing the negative attitude towards change, documentation, time constraints, increasing workload, updating faculty data and files, file organization, and training staff, student, and administrators on the concepts of accreditation. These challenges and their implications are discussed in the following paragraphs.

The finding mentioned "documentation" as one of the accreditation challenges. Many participants had difficulties in documenting or reporting the completed work for CEA. This finding is in accordance with findings reported by (Rhyan, 2013) and (Collins, 2015). The reason for considering documentation as a challenge, to Collins, is applicable in our context at the ELI. He says, "Turks do not traditionally document things and don't have defined policies and procedures, all of which made many of the CEA requirements challenging," (Collins, 2015, p. 148). The findings also revealed other challenges that are stated in the study of some researchers. These challenges included, increasing work load (Brahimi et al., 2016; Karaferye 2017), time constraints (Karaferye, 2017), filing system, raising awareness of student, faculty and staff (Rhyan, 2013), stress (Van Kemenade et al., 2010), time consumption (Brahimi et al., 2016; Rhyan 2013), and costs (Rhyan, 2013).

However, challenges can be overcome by all means of top management supports, as the findings indicated. The participants also suggested other solutions that would ease the burden of the accreditation process:

- simplifying the system for staff to be more open to change and accept new requirements,

- having accreditation orientation,

- supporting each other, 
- determination,

- transparency,

- team work,

- feeling of belonging,

- opening dialogue,

- communication between admin and faculty.

These solutions are similar to the ones mentioned in the literature. The positive influence of management support in raising motivation is emphasized by (Van Kemenade et al., 2010, p. 265), "The support of the management for accreditation is crucial ... There is not only a direct effect of (lack of) management motivation to the implementation of accreditation but also an indirect effect through (de-)motivation of the employees". Other ways to overcome challenges include increasing motivation and interaction between top management, faculty and staff, encouraging academicians to set professional as well as institutional goals (Karaferye, 2017), involvement of all in the process (Karaferye, 2017; Onsman, 2010), the sense of ownership of the quality of services to sustain improvements and the integration of accreditation into the structure and function of an organization (Rhyan, 2013).

As for the last research question, the results indicated that accreditation has a positive impact on the improvement of processes and practices on ELI management, administrative and academic levels which in turn has been successful in improving the quality of PYELP. This finding is in line with findings of previous studies; among those (Ulker and Bakioglu, 2018) who assured that accreditation contributes more to the improvement of processes and practices in newly established institutions (1-20 years) than those old established ones (more than 41 years). One may argue that the ELI at KAU was stablished for more than 40 years, however the ELI PYELP was founded for less than 20 years.

More specifically, the results revealed the impact of accreditation on ELI management improvement which included, implementation of organizational structure that lead faculty members to use the proper channels and to follow hierarchy system in all cases (e.g. student complaints). The results indicated that accreditation helped ELI members to apply and trust the institutional rules and regulations. There have been more transparent working practices, documentation, review processes, consistency, record keeping, and high standards. More importantly, time and efforts were saved.

There have been great benefits of accreditation on the admin level as well. These benefits incorporated work organization, collaboration, responsibility, clear description of job duties, improvement of working conditions, creativity, and more awareness of professional development benefits. Although admins were the ones whose accreditation burden mostly fell on to document everything and organize files; they did not take a negative view of the project. Some of the admin staff felt accreditation is a positive thing. Because of accreditation, they started to facilitate and organize the work. Accreditation also helped them to speed up the work, unify forms, become more creative and encouraged team work. This finding is also echoed in (Collins, 2015).

In addition to the positive impact of the creation of a new organizational structure, accreditation has a positive administrative effect resulting from the supportive working atmosphere. All participants agreed that there was a great improvement in ELI workplace as a result of the supportive atmosphere in which regular meetings helped to keep everyone on track and facilitate points of struggling. Thus, the workplace became healthier and the whole atmosphere was productive and helpful. It is notable that management support is crucial for the implementation of accreditation and the motivation of employees especially if their core interests are addressed and they are loyal to the institution (Van Kemenade et al., 2010). (Collins, 2015) findings also found support in this research as regards to the positive impact of accreditation on administration. However, as regards to the apparent ELI improved working conditions as a result of accreditation, there was little evidence in Collins' results as to the improved working conditions which might be affected, in his case, by staff policies related to university.

On the academic level, the benefits are anticipated to deliver better English education by providing high teaching standards, professionalism, better professional development opportunities, faculty appraisals. Improvement of cultural norms and values, and more job opportunities are also revealed among the accreditation positive effects. These effects echo the ones stated in (Collins, 2015; Van Kemenade et al., 2010) works.

Furthermore, accreditation had a positive cultural impact on the majority of staff and faculty at ELI. All interviewees were very supportive to accreditation as it addressed their core interests (Van Kemenade et al., 2010). Staff learned the importance of commitment, team work, and professional development. Thus, they became more confident and their performance was highly improved (Nguyen and Ta, 2018). Similarly, faculty 
started to evaluate themselves and looked for ways to improve themselves. Goal oriented attitude also grew at ELI. Faculty were more dedicated to achieve targeted goals. This finding is in parallel with some studies conducted by (Ulker and Bakioglu, 2018; Nguyen and Ta, 2018; Veries 2014).

More importantly, realizing the value of the review committees and keeping up the good work mentioned in the participants' responses indicated faculty and staff's awareness of accreditation as a continuous process of improvement to maintain quality (Rhyan, 2013). This idea is emphasized by $(\mathrm{Oz}, 2005)$ as quoted in (Ulker and Bakioglu, 2018, p. 8) who assured "most institutions see accreditation as a once- in-a-life-time effort and they are not aware that what is necessary in accreditation is a continuous process which will last lifelong as continuous improvement and monitoring of the system". Therefore, accreditation is a continuous effort to maintain and keep up the same level of professionalism and quality.

Although ELI has opted for numerous changes in all areas to get accreditation, the result indicated that the changes for initial accreditation were substantial than those implemented in the reaccreditation stage. This is due to the fact that establishing a whole system of quality requires more effort than maintaining it. Once changes took place only follow ups, reviews and updating documents were required in the reaccreditation stage. This finding is supported by (Ulker and Bakioglu, 2018, p. 7) who stated that "Maintaing the current state and possibly improving the program may not be as hard and time consuming as when significant changes are needed as in the initial accreditation process," and assured that positive contributions of accreditation can be much more in the initial accreditation than in the reaccreditation process.

However, changing the attitude towards changes of a few people at ELI was not an easy task. This lack of cooperation or resistance to accreditation change is typical to other contexts (e.g. Van Kemenade et al., 2010). The reasons given for this attitude include the fear of the unknown rather than outright resistance to the process of accreditation, the doubt of the accreditation outcomes (Collins, 2015), the lack of awareness, and the unwillingness to have more workloads (Van Kemenade et al., 2010). To (Onsman, 2010), the top-down hierarchical approach to change, which is adopted by most universities in the Kingdom of Saudi Arabia, can cause resistance. He further asserts that the adoption of "a networked participatory analysis approach" in which all participate can be the best solution for this resistance. (Collins, 2015) assured that, resistance can naturally be felt as international accreditation imposes cultural values and that accreditation alone cannot foster a change in faculty and staff culture i.e. attitudes; "it can be a way of kick - starting this process" (p. 144).

Imposition of accreditation ideas from the top, as one of the negative attitudes of accreditation, was not one of the challenges mentioned. This finding is on contrary to (Collins, 2015). Even though one of the interviewees mentioned that, she had to take part in the accreditation process as this was the desire of the head, her ideas soon changed when she got immersed in the process and she realized accreditation's value.

To sum up, accreditation perceptions are shaped by position in the institute and by addressing core interests. The fear of the unknown, the doubt of the accreditation outcome, lack of awareness, unwillingness to have more workloads, and top down hierarchical approach are reasons for the resistance sometimes faced towards accreditation change. Open dialogues, reliability, collaboration, involvement of all, awareness workshops and top management supports can have positive effects on admin and academics and can help in overcoming challenges faced.

In a nutshell, accreditation could be an effective tool if used properly (Collins, 2015). This idea is well versed by a faculty participant who assured "if accreditation is practiced and embraced as it should be, it will have a great impact on ELI in terms of working environment, facilities and the spirit of ELI faculty". This means true practice in reality of what is written in the self-study report, keeping up the good work and continuous improvement are at the heart of accreditation.

The importance of the above-mentioned positive effects of accreditation on ELI management, administrative and academic levels lies in the fact that they can motivate other language institutions to get accredited. Also, if the above operational challenges faced and solutions suggested are taken into consideration from the very beginning, this will help to ease the accreditation process and get the best results.

Although accreditation is a long, hard, and time consuming activity, the results are worthy the exerted effort. Therefore, it is of paramount importance to maintain the quality level reached at the time of accreditation by continuous feedback, review and improvement as accreditation is not a one-shot process; it is a continuous, everlasting effort to maintain the quality reached. Failure to understand this idea might result in accreditation withdrawal.

As for the study limitations, it is a small scale study with only a few participants in a specific context. In addition, 
it could be assumed that the researchers' positions and involvement in the process of accreditation might have affected the research as the participants might have responded in the way they thought the researchers wanted to hear. However, there was no other way to conduct the research and the advantages of being fully aware of the accreditation process outweighed this effect (Collins, 2015).

It is recommended that future research measures accreditation impact in class and on student learning outcomes on a larger scale of participants from different contexts (Collins, 2015). Students' feedback is essential as they are the most important stakeholders whom the program serves and the quality improvement is for (Almusallam, 2013). Data from this research would greatly enhance the relevance and validity of this study.

\section{Acknowledgement}

The authors would like to thank all the participants who spared some of their time for interviews. They also want to single out for special acknowledgment the Deanship of Scientific Research (DSR) at King Abdulaziz University, who sponsored and supported this project (\# 38-270-154) technically and financially.

\section{References}

Al Mohaimeed, A., Midhet, F., Barrimah, I., \& Saleh, M. N. E. D. (2012). Academic Accreditation Process: Experience of a Medical College in Saudi Arabia. International Journal of Health Sciences, Qassim University, 6(1), 24-29. Retrieved from https://ijhs.org.sa/index.php/journal/article/view/343

Almusallam, A. (2013). Accreditation and Quality Assurance in Post-Secondary Education in the Kingdom of Saudi Arabia. Journal of Higher Education and Science, 3(3), 193-199. https://doi.org/10.5961/jhes.2013.076

Brahimi, T., Sarirete, A., \& Ibrahim, R. (2016). The Impact of Accreditation on Student Learning Outcomes. International Journal of Knowledge Society Research, 7(4), 51-62. https://doi.org/10.4018/IJKSR.2016100105

Collins, I. (2015). Using International Accreditation in higher education to effect changes in organizational culture: A case study from a Turkish University. Journal of Research in International Education, 14(2), 141-154. https://doi.org/10.1177/1475240915592589

Commission on English Language Program Accreditation (CEA) (n.d.) (2018). Accreditation Overview. Retrieved from http://www.cea-accredit.org/accreditation

Dey, N. (2011). Quality Assurance and Accreditation in Higher Education in India. Academic Research International, 1(1), 104-110. https://doi.org/10.1080/21568235.2011.617567

Fertig, M. (2007). International school accreditation, Between a rock and a hard place?. Journal of Research in International Education, 6(3), 333-348. https://doi.org/ 10.1177/1475240907083199

Harvey, L. (2002). Evaluation for what?. Teaching in Higher Education, 7(3), 245-264. https://doi.org/10.1080/13562510220144761

Karaferye, F. (2017). An Introduction to program Accreditation in Foreign Language Schools in Turkey. European Journal of Multidisciplinary studies, 4(2), 62-66.https://doi.org/ 10.26417/ejms.v4i2

Nazrul Islam, G., Ali, M., \& Zohurul Islam, M. (2017). Quality Assurance and Accreditation Mechanisms of Higher Education Institutions: Policy issues and Challenges in Bangladesh. European Journal of Education, 3(5), 278-304. https://doi.org/10.5281/zenodo.495792

Nguyen, H. C., \& Ta, H. (2018). Exploring impact of accreditation on higher education in developing countries: A Vietnamese view. Tertiary Education and Management, 24(2), 154-167. https://doi.org/10.1080/13583883.2017.1406001

Onsman, A. (2010). Dismantling the Perceived Barriers to the Implementation of National Higher Education Accreditation Guidelines in the Kingdom of Saudi Arabia. Journal of Higher Education Policy and Management, 32(5), 511-519. https://doi.org/10.1080/1360080X.2010.511123

Oz, H. (2005). Accreditation Process in Turkish Higher Education. Higher Education in Europe, 30(3-4), 335-44. https://doi.org/ 10.1080/03797720600625960

Ryhan, E. (2013). Towards Accreditation in Higher Education: A case study of Jazan Community College (JCC), KSA. International interdisciplinary Journal of Education, 2(1), 89-95. https://doi.org/10.12816/0002920

Sywelem, M. (2014). Accreditation Models in Teacher Education: The cases of United States, Australia and India. International Journal of Education and Research, 2(3), 1-12. 
Veries, M. (2014). International Accreditation of PA programs: Narrations of an Evaluator. The NISPACEE Journal of Public Administration and Policy, VI(2), 97-113. https://doi.org/10.2478/nispa-2013-0008

Van Kemenade, E., \& Teun, W. H. (2010). A Critique of the Use of Self-Evaluation in a Compulsory Accreditation System. Quality in Higher Education, 16(3), 257-268. https://doi.org/10.1080/13538322.2010.506715

Ulker, N., \& Bakioglu, A. (2018). An international research on the influence of accreditation on academic quality. Studies in Higher Education. https://doi.org/10.1080/03075079.2018.1445986

http://cea-accredit.org/about-cea/standards

http://cea-accredit.org/about-cea/policies-and-procedures

\section{Copyrights}

Copyright for this article is retained by the author(s), with first publication rights granted to the journal.

This is an open-access article distributed under the terms and conditions of the Creative Commons Attribution license (http://creativecommons.org/licenses/by/4.0/). 